\title{
Adenovirus-mediated IL-24 expression enhances the chemosensitivity of multidrug-resistant gastric cancer cells to cisplatin
}

\author{
ZONGLEI MAO ${ }^{1 *}$, GUOCHUN BIAN ${ }^{3 *}$, WEIHUA SHENG ${ }^{2}$, \\ SONGBIN HE $^{1}$, JICHENG YANG ${ }^{2}$ and XIAOQIANG DONG ${ }^{1}$ \\ ${ }^{1}$ Department of General Surgery, The First Affiliated Hospital of Soochow University; \\ ${ }^{2}$ Cell and Molecular Biology Institute, College of Medicine, Soochow University, Suzhou, Jiangsu; \\ ${ }^{3}$ The Second People's Hospital of Kunshan, Kunshan, Suzhou, Jiangsu, P.R. China
}

Received June 27, 2013; Accepted August 2, 2013

DOI: $10.3892 /$ or.2013.2695

\begin{abstract}
Chemotherapy is one of the commonly used strategies in gastric cancer, especially for unresectable patients, but it becomes insensitive to repeated administration of even the most effective chemotherapeutic agents, such as cisplatin. Given this, there is an urgent need for developing chemosensitizers to overcome acquired resistance to chemotherapeutic agents. Interleukin-24 (IL-24), a cytokine-tumor suppressor, shows broad-spectrum and tumor-specific antitumor properties, and studies have demonstrated that IL-24 could conspicuously restore the chemosensitivity of MDR cancer cells. Herein, we developed a human MDR gastric cancer cell subline, SGC7901/ CDDP, by repeated selection of resistant clones of parental sensitive cells, and further investigated the chemosensitizing effects and the underlying mechanisms of adenovirus-mediated IL-24 (Ad-IL-24) gene therapy plus CDDP for the human MDR gastric cancer cells SGC7901/CDDP in vitro and in vivo. The results demonstrated that the expression of IL-24 mRNA and protein was profoundly downregulated in SGC7901/CDDP cells by RT-PCR and western blot analysis. In addition, the cell
\end{abstract}

Correspondence to: Dr Xiaoqiang Dong, Department of General Surgery, The First Affiliated Hospital of Soochow University, No. 188 Shizi Street, Suzhou, Jiangsu 215006, P.R. China

E-mail: dongxq@hotmail.com

Dr Jicheng Yang, Cell and Molecular Biology Institute, College of Medicine, Soochow University, No. 123 Renai Road, Suzhou Industry Park, Suzhou, Jiangsu 215123, P.R. China

E-mail: jcyang@suda.edu.cn

*Contributed equally

Abbreviations: MDR, multidrug resistance; P-gp, P-glycoprotein; RT-PCR, reverse transcriptase polymerase chain reaction; $\mathrm{IC}_{50}, 50 \%$ inhibitory concentration

Key words: interleukin-24, gastric cancer, chemosensitivity, cisplatin viability assay showed that the $\mathrm{IC}_{50}$ of SGC7901/CDDP cells to CDDP, 5-FU, ADM and MTX was significantly enhanced compared to parental sensitive SGC7901 cells. Ad-IL-24induced IL-24 overexpression decreased the $\mathrm{IC}_{50}$ of the above agents (not MTX), induced $\mathrm{G}_{2} / \mathrm{M}$ cell cycle arrest, and Ad-IL-24 plus CDDP elicited significant apoptosis and tumor suppression of SGC7901/CDDP cells in vitro and SGC7901/ CDDP cell xenograft tumors in vivo, respectively. Moreover, our results demonstrated that the mechanisms of Ad-IL-24elicited chemosensitizing effects were closely associated with a substantial upregulation of Bax and downregulation of $\mathrm{P}-\mathrm{gp}$ and Bcl-2 in SGC7901/CDDP cells in vitro and SGC7901/ CDDP xenograft tissues in vivo. Thus, this study indicates that overexpression of IL-24 gene can significantly promote chemosensitivity in MDR phenotype SGC7901/CDDP gastric cancer cells.

\section{Introduction}

Gastric cancer is the fourth leading cause of cancer-related death in the world (1). To date, chemotherapy is the most frequently used fundamental treatment for gastric cancer. However, the main barrier to successful chemotherapy is MDR caused by insensitivity to multiple chemotherapeutic agents after exposure to a single chemotherapeutic drug (2). For decades, the most representative consensus is the overexpression of drug efflux pumps (such as P-gp) occupying a critical position in development of MDR. Consequently, several innovative chemosensitizers against P-gp, such as verapamil, trifluoperazine and cyclosporine, have been found to enhance chemosensitivity of MDR phenotype cancer cells (3). However, the clinical application of these chemosensitizers showed disappointing results $(4,5)$, indicating that there are some unknown molecules and mechanisms also responsible for MDR. Recent studies have verified that some novel factors including defective apoptosis pathway, enhanced DNA repair activity, or altered metabolism of drugs play a critical role in promoting formation of MDR (6). Though the underlying mechanisms have been deeply studied in vitro and in vivo (6-9), the precise mechanisms involved in MDR have not been 
fully characterized. Evidence so far suggest that mechanisms responsible for MDR in gastric cancer are likely to be multifaceted and extremely intricate. Thus, further investigation of the MDR mechanisms to find acceptable chemosensitizers for clinical application in human cancers, including gastric cancer is required.

Interleukin-24 (IL-24), a novel member of interleukin-10 family of cytokines, also known as melanoma differentiation associated gene-7 (mda-7), was first identified by using subtraction hybridization of cDNA libraries from actively proliferating human HO-1 melanoma cells versus interferon- $\beta$ and mezerein-treated HO-1 cells (10). It can specifically induce apoptosis in a wide variety of malignant tumor cells exerting no discernible toxic effects towards normal cells by eliciting potent 'antitumor bystander activity' as a consequence of autocrine secretion (11), which has attracted particular attention from researchers worldwide. Subsequently studies demonstrated that expression of IL-24 was lost in a broad spectrum of malignant tumors including gastric cancer, whereas ectopic expression of this gene performed a ubiquitous growth inhibition, apoptosis induction, reversal malignant phenotype and terminal differentiation in a variety of cancers $(10,12-17)$. These gratifying findings have led to the development of INGN241, a replication-incompetent IL-24-expressing adenovirus, which is currently in phase II/III clinical trials (18).

Previous studies showed that combination of chemotherapy, radiotherapy and other conventional therapies with gene therapy is a promising practice in cancer treatment (19-21). Furthermore, adenoviral p53 gene was in adjuvant use with conventional chemotherapy, radiation therapy, and surgery of lung and head and neck cancers (22). IL-24 has been reported to sensitize human colorectal cancer cells to doxorubicin and 5-fluorouracil, human melanoma cells to dacarbazine, and human hepatocellular carcinoma cells to 5-fluorouracil, respectively $(3,17,23,24)$. In addition, our laboratory demonstrated that adenovirus-mediated IL-24 gene therapy could enhance chemosensitivity of MDR phenotype colon cancer cells to oxaliplatin (25). However, its chemosensitizing effects for human MDR phenotype gastric cancer cells so far have not been reported. Given this, we successfully established the CDDP-induced MDR phenotype gastric cancer cell subline and hypothesized that IL-24 gene may sensitize these human gastric cancer cells to cisplatin therapy. In this study, we also investigated the possible role of IL-24 in chemosensitizing of human gastric cancer cells and its underlying mechanisms.

\section{Materials and methods}

Adenoviral vectors, cell lines, reagents and mice. The Ad-IL-24 and Ad-GFP adenoviral vectors were constructed in our laboratory (26). The human embryonic kidney cell line QBI-293A was kindly provided by Professor Jiang Zhong of Fudan University (Shanghai, China). The human gastric cancer cell line SGC7901 was purchased from the American Type Culture Collection (ATCC, Rockville, MD, USA). The QBI-293A and SGC7901 cell lines were cultured in RPMI1640 medium (Gibco, Shanghai, China) supplemented with $10 \%$ fetal bovine serum (FBS) (Hyclone, Logan, UT, USA). The TRIzol reagent and the reverse transcriptase MuMLV were purchased from Invitrogen (Shanghai, China). The cell counting kit-8 was purchased from the subsidiary of Dojindo Laboratories (Shanghai, China). The Annexin V-PE/7-AAD apoptosis detection kit was purchased from BD Biosciences (Shanghai, China). The in situ cell death detection kit was purchased from Roche Applied Science (Shanghai, China). The monoclonal anti-IL-24 antibody and human IL-24 enzyme-linked immunosorbent assay (ELISA) kit were purchased from R\&D Systems (Shanghai, China). The antibodies specific for P-gp, Bax, Bcl-2 were from Cell Signaling Technology (Boston, MA, USA). The SuperEnhanced chemiluminescence detection kit was from Applygen Technologies Inc. (Beijing, China). The UltraSensitive ${ }^{\mathrm{TM}}$ SP kit was obtained from Maixin (Fuzhou, China). Chemotherapeutical drugs cisplatin (CDDP), 5-fluorouracil (5-FU), adriamycin (ADM) and methotrexate (MTX) were kindly provided by The First Hospital Affiliated of Soochow University (Suzhou, China). Additionally, female athymic nude mice were purchased from Shanghai Experimental Animal Center (Shanghai, China) and maintained in the animal facility at Soochow University according to the animal research committee's guidelines of Soochow University.

Development of the MDR phenotype human gastric cancer cell subline SGC7901/CDDP. Gastric cancer SGC7901 cells were cultured in RPMI-1640 supplemented with 10\% FBS overnight and then changed to cisplatin-containing medium to induce MDR by repeated selection of resistant clones of parental sensitive SGC7901 cells to stepwise increasing concentrations of cisplatin. After 4 months, the SGC7901 cells could stably grow in $1 \mu \mathrm{g} / \mathrm{ml}$ cisplatin-containing medium. To maintain the MDR phenotype, the $1 \mu \mathrm{g} / \mathrm{ml}$ cisplatin-containing medium was used in later MDR phenotype cell culture.

Transfection. To assess the optimal multiplicity of infection (MOI) for a maximal infection and transgene expression, human gastric cancer cells SGC7901/CDDP were infected with Ad-IL-24 and Ad-GFP at various MOIs (0, 1, 10, 25, 50, 100 and 200) for $24 \mathrm{~h}$. The adenoviral infection efficiency was analyzed according to GFP expression by fluorescence microscopy. Furthermore, the IL-24 transgene expression mediated by adenoviral infection in SGC7901/CDDP cells was determined by using RT-PCR and western blot analysis.

RT-PCR analysis. Total RNA was extracted from Ad-IL-24or Ad-GFP-infected and uninfected SGC7901/CDDP cells using TRIzol and then reversely transcribed into cDNA using Oligo $\mathrm{d}(\mathrm{T}) 18$ as primer according to the manufacturer's protocol. PCR amplification was carried out using these cDNA samples as templates and IL-24 primers (5'-GCACTCGAGC CATGAATTTTCAACAGAGGCTGCA-3' and 5'-GCTTCT AGATCAGAGCTTGTAGAATTTCTG-3') under conditions of an initial cycle at $94^{\circ} \mathrm{C}$ for $2 \mathrm{~min}$ and $72^{\circ} \mathrm{C}$ for $10 \mathrm{~min}$ followed by 35 cycles at $94^{\circ} \mathrm{C}$ for $50 \mathrm{sec}, 58^{\circ} \mathrm{C}$ for $50 \mathrm{sec}$ and $72^{\circ} \mathrm{C}$ for $55 \mathrm{sec}$ and a final extension at $72^{\circ} \mathrm{C}$ for $10 \mathrm{~min}$. The PCR products were separated in $1 \%$ agarose gels using electrophoresis with ethidium bromide staining. Subsequently, The GAPDH as well as multidrug resistant- and apoptosisrelated genes MDR1, Bax and Bcl-2 were detected as the above protocols, the PCR reaction was carried out using the 
following primers (5'-GCGGCTCCGATACATGGTT-3' and 5'-TGGCGAGCCTGGTAGTCAAT-3' for MDR1; 5'-GGA TGCGTCCACCAAGAA-3' and 5'-GCACTCCCGCCA CAAAGA-3' for Bax; 5'-TGTGGCCTTCTTTGAGT TCG-3' and 5'-CTACCCAGCCTCCGTTATCC-3' for Bcl-2; 5'-TTACTCCTTGGAGGCCATGTGGGCC-3' and 5'-ACT GCCACCCAGAAGACTGTGGATGG-3' for human GAPDH).

Western blot analysis. Total proteins was isolated from Ad-IL24- or Ad-GFP-infected and uninfected SGC7901/CDDP cells and resolved in $12 \%$ sodium dodecyl sulfate-polyacrylamide gel electrophoresis (SDS-PAGE) and subsequently transferred onto a polyvinylidene difluoride membrane. After that, the membrane was incubated in 5\% (w/v) non-fat dry milk in Tris-buffered saline containing $0.05 \%$ Tween-20 (TBST) for $1 \mathrm{~h}$ at $37^{\circ} \mathrm{C}$ and then further with a panel of primary antibodies specific for IL-24, P-gp, Bax, Bcl-2 and GAPDH (an internal control) in blocking solution for $1 \mathrm{~h}$ at $37^{\circ} \mathrm{C}$. The membrane was then washed with TBST and incubated with a peroxidase horseradish peroxidase-conjugated secondary antibody in blocking solution for another $1 \mathrm{~h}$ at $37^{\circ} \mathrm{C}$. After three washes with TBST, the positive bands were developed by using a SuperEnhanced chemiluminescence detection kit and visualized after exposure of the membranes to Kodak X-ray film.

ELISA analysis. The adenovirus-mediated secretory expression of IL-24 in SGC7901/CDDP cells was detected by ELISA analysis. Briefly, the SGC7901/CDDP cells $\left(2.5 \times 10^{6}\right)$ were infected with 100 MOI Ad-IL-24, Ad-GFP or without adenovirus (PBS) in $10 \mathrm{ml}$ medium, respectively. After $24 \mathrm{~h}$ of treatment, the cellular culture supernatants generated from the three groups were collected, and the amount of IL-24 in above culture supernatants was analysed by ELISA using human IL-24 ELISA kit according to the manufacturer's instructions.

CCK-8 assay. The in vitro resistance index of SGC7901/CDDP cells were analyzed by CCK-8 assay. Briefly, SGC7901 and SGC7901/CDDP cells ( $1 \times 10^{4}$ per well) were seeded in 96-well culture plates and incubated for $24 \mathrm{~h}$ at $37^{\circ} \mathrm{C}$ and then treated with CDDP, 5-FU, ADM and MTX in seven different concentrations for $48 \mathrm{~h}$ (see Results). The viability of SGC7901 and SGC7901/CDDP cells were then analyzed by using CCK-8 kit according to the manufacturer's protocol. Similarly, the cells infected with Ad-IL-24 and Ad-GFP were also included for CCK-8 assay. The SGC7901/CDDP cells were infected with 100 MOI Ad-IL-24 or Ad-GFP or without adenovirus (PBS) for $24 \mathrm{~h}$ and then treated with CDDP, 5-FU, ADM and MTX for $48 \mathrm{~h}$ and then subjected to CCK-8 assay. Inhibitory rate (\%) was calculated using the formula: $1-\left(\mathrm{OD}_{\text {experiments }} / \mathrm{OD}_{\text {controls }}\right)$ $\mathrm{x} 100 \%$; Resistance index: $\mathrm{IC}_{50(\mathrm{SGC} 7901 / \mathrm{CDDP})} / \mathrm{IC}_{50(\mathrm{SGC} 7901)}$ and Reversion index: $\mathrm{IC}_{50(\mathrm{PBS})} / \mathrm{IC}_{50(\mathrm{Ad}-\mathrm{IL}-24}$ ).

Flow cytometric analysis of cell cycle alteration. The SGC7901/CDDP human gastric cancer cells $\left(1 \times 10^{6}\right)$ were cultured with 100 MOI Ad-IL-24, Ad-GFP or without adenovirus (PBS), respectively. After $48 \mathrm{~h}$, the infected and uninfected SGC7901/CDDP cells were trypsinized and washed in cold PBS, then subjected to cold $70 \%$ ethanol for
$12 \mathrm{~h}$, and the cells were stained with propidium iodide for cell cycle analysis by flow cytometry. All experiments were repeated three times.

Analysis of in vitro and in vivo chemosensitizing effects. To test the chemosensitizing effects of Ad-IL-24 in vitro and in vivo, the following groups were studied: PBS+SGC7901/ CDDP (PBS), Ad-GFP+SGC7901/CDDP (Ad-GFP), Ad-IL24+SGC7901/CDDP (Ad-IL-24), CDDP+SGC7901/CDDP (CDDP), Ad-GFP+CDDP+SGC7901/CDDP (Ad-GFP+CDDP) and Ad-IL-24+CDDP+SGC7901/CDDP (Ad-IL-24+CDDP). Firstly, we investigated in vitro effects. The SGC7901/CDDP cells $\left(2.5 \times 10^{5}\right)$ were cultured in 6-well culture plates (marked A, B, C, D, E and F, respectively), After $24 \mathrm{~h}, 100 \mathrm{MOI}$ Ad-IL-24 was added in A and B well, 100 MOI Ad-GFP was added in $\mathrm{C}$ and $\mathrm{D}$ well, equivalent $\mathrm{PBS}$ was added in $\mathrm{E}$ and $\mathrm{F}$ well as controls. After next $24 \mathrm{~h}, 2.5 \mu \mathrm{g} / \mathrm{ml}$ CDDP was added in $\mathrm{A}, \mathrm{C}$ and $\mathrm{E}$ wells. Two days later, all treatment groups were harvested and washed in cold PBS, the apoptosis rate was assessed by flow cytometry using the Annexin V-PE/7-AAD apoptosis detection kit according to the manufacturer's protocol. Briefly, the SGC7901/CDDP cells $\left(2.5 \times 10^{5}\right)$ were incubated with $5 \mu 1$ of Annexin V-PE and $5 \mu 1$ 7-AAD in $100 \mu 1$ of $1 \mathrm{X}$ Annexin V-binding buffer at room temperature. After incubating for $15 \mathrm{~min}, 400 \mu \mathrm{l}$ of $1 \mathrm{X}$ binding buffer was added, and the apoptotic cells were analyzed by flow cytometry.

Secondly, we investigated in vivo effects. The female athymic nude mice were subcutaneously (s.c.) inoculated into the armpits of their right anterior limbs with $2 \times 10^{6}$ human SGC7901/CDDP cells. After the tumor mass reached a mean tumor volume of $\sim 100 \mathrm{~mm}^{3}$, Ad-IL-24, Ad-GFP or PBS were given once every 3 days by intratumoral injection for 36 days. From days $7-14$ and $21-28,4.5 \mathrm{mg} / \mathrm{kg}$ of CDDP was given via tail vein injection weekly. Tumor progression and regression were monitored and tumor volume was measured with a caliper every four days. The tumor volume was calculated by a formula, i.e., $a b^{2} / 2$, where $a$ is the larger and $b$ is the smaller of the two dimensions. The tumor-bearing mice were then sacrificed at day 36 after the treatments and tumor xenograft tissues were removed, weighed, fixed by $10 \%$ neutral formalin, and then embedded in paraffin for hematoxylin and eosin staining and immunohistochemical analysis.

Immunohistochemistry. Expression of $\mathrm{P}-\mathrm{gp}, \mathrm{Bax}$ and $\mathrm{Bcl}-2$ proteins of PBS, Ad-GFP and Ad-IL-24 groups in human gastric cancer xenograft tissues was analyzed by using immunohistochemistry with an UltraSensitive SP kit according to the manufacturer's instructions. The presence of buffy or brown diaminobenzidine precipitates is indicative of positive reactivity. The integral optical density (IOD) of immunohistochemical intensity was analyzed by Image-Pro Plus 6.0 software (Media Cybernetics, Bethesda, MD, USA).

Statistical analysis. All data were presented as the mean \pm SD. The significant difference between two groups was evaluated by using Student's t-test and one-way or two-way repeated measures analysis of variance and multiple comparisons with SPSS 10.0 software (SPSS, Chicago, IL, USA). A value of $\mathrm{P}<0.05$ was considered to be significant. 


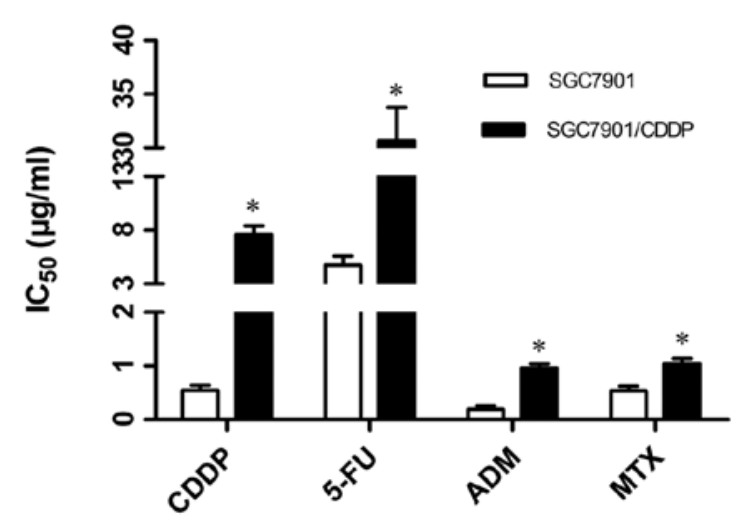

Figure 1. Identification of the chemosensitivity of gastric cancer cell subline SGC7901/CDDP to chemotherapeutic drugs, The IC $_{50}$ of SGC7901 and SGC7901/CDDP cells to CDDP, 5-FU, ADM and MTX were determined by using CCK- 8 assay as described in Materials and methods. ${ }^{*} \mathrm{P}<0.05$ compared to parental sensitive SGC7901 cells. Data shown are representative of three independent experiments. Statistical analysis was performed by Student's t-test.

\section{Results}

Development of the CDDP-induced MDR phenotype gastric cancer cell subline SGC7901/CDDP. To obtain CDDP-induced MDR phenotype gastric cancer cell subline SGC7901/CDDP, we selected the SGC7901 cells repeatedly under increased cisplatin concentrations from $0.04 \mu \mathrm{g} / \mathrm{ml}$ to $1 \mu \mathrm{g} / \mathrm{ml}$ in a 4 months period. The MDR phenotype gastric cancer cells could grow stably in $1 \mu \mathrm{g} / \mathrm{ml}$ cisplatin-containing medium. To maintain the MDR phenotype, $1 \mu \mathrm{g} / \mathrm{ml}$ cisplatin-containing medium was used in later MDR phenotype cell cultures. We first performed CCK-8 assay to detect the changed viability in SGC7901/CDDP cells. The data showed that SGC7901/ CDDP cells acquired 14.03-, 6.47-, 5.06- and 1.94-fold resistance to CDDP, 5-FU, ADM and MTX compared to parental SGC7901 cells, respectively $(\mathrm{P}<0.05$; Fig. 1$)$.

Stable expression of IL-24 in vitro. To assess the optimal MOI for a maximal transgene expression with minimal adenovirus itself-caused cytotoxicity, SGC7901/CDDP cells were infected with Ad-IL-24 or Ad-GFP at different MOIs (see Materials and methods) and examined under fluorescence microscopy. More than $90 \%$ of GFP expression was found in the Ad-IL-24- or Ad-GFP-infected SGC7901/CDDP cells at MOI of 100 or above, whereas the GFP expression was not found in uninfected SGC7901/CDDP cells. Additionally, there was rarely adenovirus-elicited cytotoxic effect in 100 MOI blank Ad-GFP-infected SGC7901/CDDP cells (data not shown). Furthermore, adenovirus-mediated exogenous IL-24 tumor suppressor gene and protein was significant expressed at 100 MOI in Ad-IL-24-infected SGC7901/CDDP cells but not in Ad-GFP-infected and uninfected SGC7901/ CDDP cells (Fig. 2a and b), indicating that IL-24 is expressed in Ad-IL-24-transfected SGC7901/CDDP cells at transcriptional and translational levels. In addition, a significant amount of secreted IL-24 was found in the culture supernatants of Ad-IL-24 infected SGC7901/CDDP cells but not in the Ad-GFP infected or uninfected SGC7901/CDDP cells $(\mathrm{P}<0.05$; Fig. 2c). These results suggested that $100 \mathrm{MOI}$ can
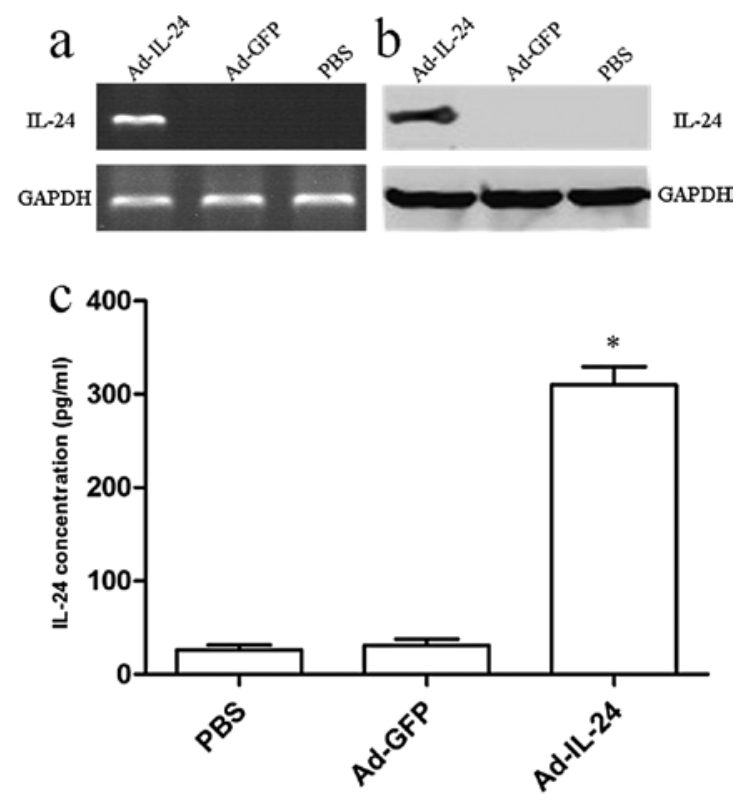

Figure 2. Adenovirus-mediated IL-24 expression in SGC7901/CDDP gastric cancer cells. (a) RT-PCR. Total RNA was obtained from Ad-IL-24- or Ad-GFP-infected and uninfected SGC7901/CDDP cells and subjected to RT-PCR. A housekeeping gene GAPDH was used as an internal control. (b) Western blotting. Total cellular lysates of Ad-IL-24- or Ad-GFP-infected and uninfected SGC7901/CDDP cells were analyzed by immunoblotting with an anti-IL-24 or anti-GAPDH antibody. (c) Adenovirus-mediated IL-24 secretory expression by ELISA analysis. The cellular culture supernatants generated from Ad-IL-24- and Ad-GFP-infected and uninfected SGC7901/CDDP cells were collected, and the amount of IL-24 in the culture supernatants was detected by ELISA using human IL-24 ELISA kit. ${ }^{*} \mathrm{P}<0.05$ compared with PBS and Ad-GFP group, one-way repeated measures ANOVA and multiple comparisons, $n=3$ replicates per condition, $n=3$ replicates per sample. Data shown are representative of three independent experiments.

be used as an optimal dose for the adenovirus-mediated IL-24 gene induction and transgene expression in human gastric cancer SGC7901/CDDP cells.

Ad-IL-24 significantly enhances chemosensitivity of SGC7901/ $C D D P$ cells to cisplatin in vitro and in vivo. Based on the development of MDR phenotype SGC7901/CDDP cells, we further explored whether Ad-IL-24 had chemosensitizing effects on SGC7901/CDDP cells. In vitro, Annexin V-PE and 7-AAD double-positive staining by flow cytometry showed that Ad-IL-24 plus CDDP could induce greater early apoptosis (28.13\%) than Ad-IL-24 (9.77\%) or CDDP (10.83\%) alone $(\mathrm{P}<0.05$ Fig. 3a), indicating that Ad-IL-24 treatment could significantly enhance the chemosensitivity of SGC7901/CDDP cells to cisplatin. To further address the potential chemosensitizing effects of Ad-IL-24 on SGC7901/CDDP cells, in vivo, we injected SGC7901/CDDP cells into athymic nude mice and then injected Ad-IL-24, Ad-GFP or PBS and treatment continued with or without CDDP. The data showed that Ad-IL-24 plus CDDP significantly reduced tumor volume from days 12-36 compared to the other groups $(\mathrm{P}<0.05$; Fig. $3 \mathrm{~b})$. Similarly, the tumors weight also showed a difference in Ad-IL-24 plus CDDP treatment group $(\mathrm{P}<0.05$; Fig. 3c), indicating that Ad-IL-24 also has a robust chemosensitizing effect on gastric cancer SGC7901/ CDDP cell xenografts in vivo in an athymic nude mouse model. 

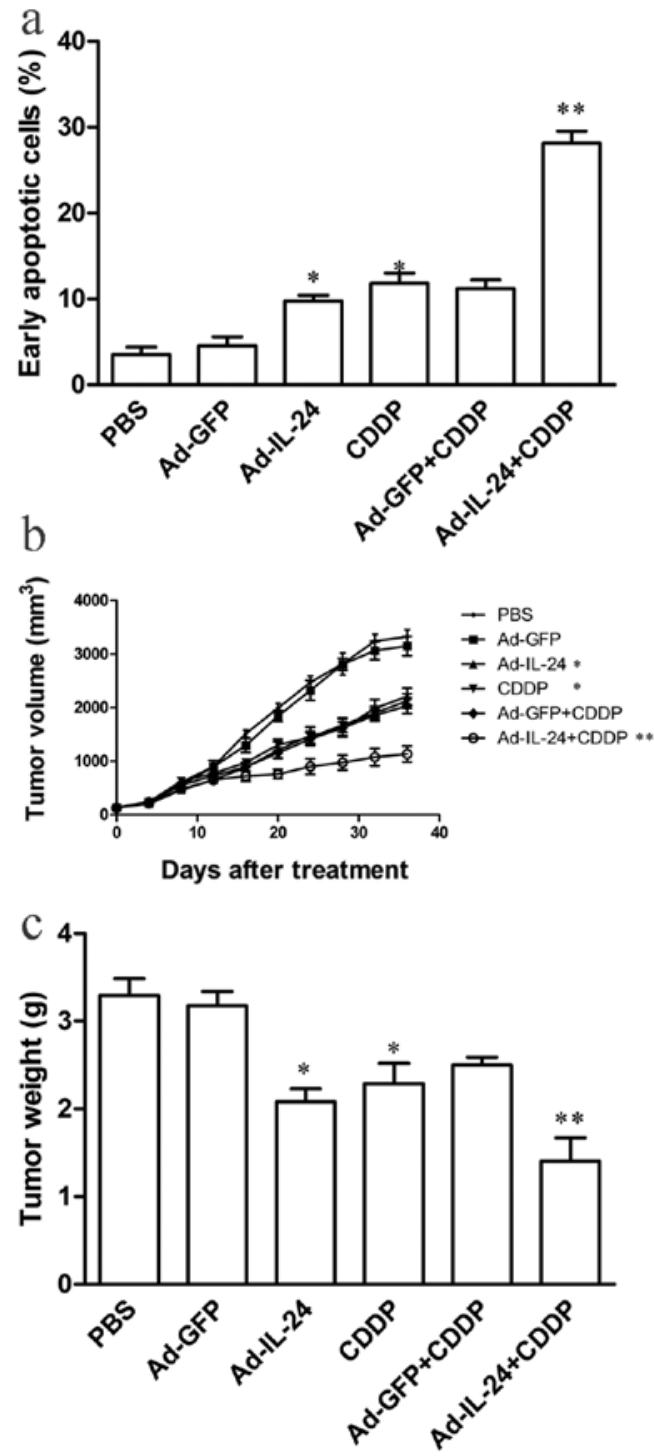

Figure 3. Chemosensitizing effects of Ad-IL-24 on SGC7901/CDDP cells in vitro and in vivo. (a) Flow cytometric analysis of apoptosis using Annexin V-PE and 7-AAD double staining. The Annexin V single-positive cells in the total population represented early apoptotic cells. "P<0.05 compared with PBS and Ad-GFP groups; ${ }^{* *} \mathrm{P}<0.05$ compared with Ad-IL-24 and CDDP groups, one-way repeated measures ANOVA and multiple comparisons, $n=3$ replicates per condition. (b and c) Tumor volume and weight. The athymic nude mice bearing gastric cancer cell SGC7901/CDDP xenograft tumors were intratumorally injected with Ad-IL-24 (1x10 $\left.{ }^{8} \mathrm{GTU}\right)$, Ad-GFP $\left(1 \times 10^{8} \mathrm{GTU}\right)$, PBS or CDDP alone, or CDDP plus intratumoral injection of Ad-IL-24 $\left(1 \times 10^{8} \mathrm{GTU}\right)$ or Ad-GFP $\left(1 \times 10^{8} \mathrm{GTU}\right)$ as described in Materials and methods. The tumor volume (b) before and after treatment, and tumor weight (c) at 36 days after treatment. $\mathrm{P}<0.05$ compared to PBS and Ad-GFP groups; ${ }^{* *} \mathrm{P}<0.05$ compared to Ad-IL-24 and CDDP groups, respectively. One-way and two-way repeated ANOVA measures and multiple comparisons ( $\mathrm{n}=5$ mice per condition). Data shown are representative of three independent experiments.

Ad-IL-24 elicits chemosensitizing effect by induction of cell cycle alteration and reversal of expression of multidrug resistant- and apoptosis-related proteins. We first investigated the changes in $\mathrm{IC}_{50}$ elicited by Ad-IL-24 in MDR phenotype gastric cancer cells. The SGC7901/CDDP cells were infected with Ad-IL-24 or Ad-GFP at 100 MOI, cell viability was determined on the fourth day by using CCK- 8 assay. Compared with Ad-GFP and PBS treatment groups, the $\mathrm{IC}_{50}$
(Fig. 4a) of the Ad-IL-24-infected SGC7901/CDDP cells to CDDP, 5-FU, ADM (not MTX) was significantly decreased. To further address the underlying mechanisms that may be responsible for Ad-IL-24-mediated chemosensitizing effect. We analyzed the cell cycle distribution and the changes of multidrug resistant- and apoptosis-related protein expression. The cell cycle alteration of SGC7901/CDDP cells in Ad-IL-24 or Ad-GFP or PBS treatment group was analyzed by flow cytometry.

As shown in Fig. 4b and c, the proportion of SGC7901/CDDP cells in the $\mathrm{G}_{2} / \mathrm{M}$ phase was significant increased in Ad-IL-24 treatment group compared with Ad-GFP and PBS groups $(\mathrm{P}<0.05)$. Subsequently, the expression of MDR- and apoptosis-related genes/proteins (MDR1/P-gp, Bax/Bax and Bcl-2/Bcl-2) were detected by RT-PCR and western blot analysis in these cells. Our results showed that MDR1/P-gp and Bcl-2/Bcl-2 were downregulated, whereas Bax/Bax was upregulated in Ad-IL-24-treated SGC7901/CDDP cells compared to PBS and Ad-GFP groups $(\mathrm{P}<0.05 ;$ Fig. 5a and b). Furthermore, expression of multidrug resistant-related proteins P-gp and apoptosis-related proteins $\mathrm{Bax}$ and $\mathrm{Bcl}-2$ was also modulated in nude xenograft tissues ( $\mathrm{P}<0.05$; Fig. 6). Those results indicate that Ad-IL-24 is a strong chemosensitizer for MDR phenotype gastric cancer SGC7901/CDDP cells.

\section{Discussion}

Chemotherapy is one of the most conventional therapeutic strategies for human cancers, but MDR is frequently a major impediment to the successful use of cancer chemotherapy (27). MDR refers to phenomenon by which cancer cells that have been exposed to a certain chemotherapeutic drug, develop cross-resistance to a variety of functionally unrelated reagents. Naturally, MDR plays a mainstay role in chemoresistance of gastric cancer treatment. Different drugs may finally induce the MDR phenotype but through various signaling pathways, consequently leading to apparently different expression or functional changes of involved molecules. Previous studies have shown that several known proteins (such as P-glycoprotein, RhoE, GAS1, thymidylate synthase Bax and Bcl-2) play an important role in development of VCR-, 5-fluorouracil- or doxorubicin-based MDR phenotype gastric cancer cells $(6,28-31)$, therefore, we speculate that different chemosensitizers may work through these known or some unknown ways to restore chemosensitivity of tumor MDR cells. Cisplatin, cis-diamminedichloroplatinum (CDDP), is deemed to be the 'penicillin of cancer drugs' due to its universal, early, and effective treatment for many cancers, including gastric cancer (32). However, the inherent or acquired resistance of tumors to CDDP therapy is a major clinical problem. The dose that is necessary to overcome even a small increase in cellular resistance can result in severe cytotoxicity in normal cells. Given this, it is imperative to explore novel chemosensitizers to reduce drug dosage, minimize side effects, enhance the efficacy of therapy, and promote the application of cisplatin in MDR phenotype cancer therapy.

Gene therapy provides a viable option, especially when used with a cancer-selective apoptosis-inducing gene, such as interleukin-24 (IL-24), a unique member of the IL-10-related 
a

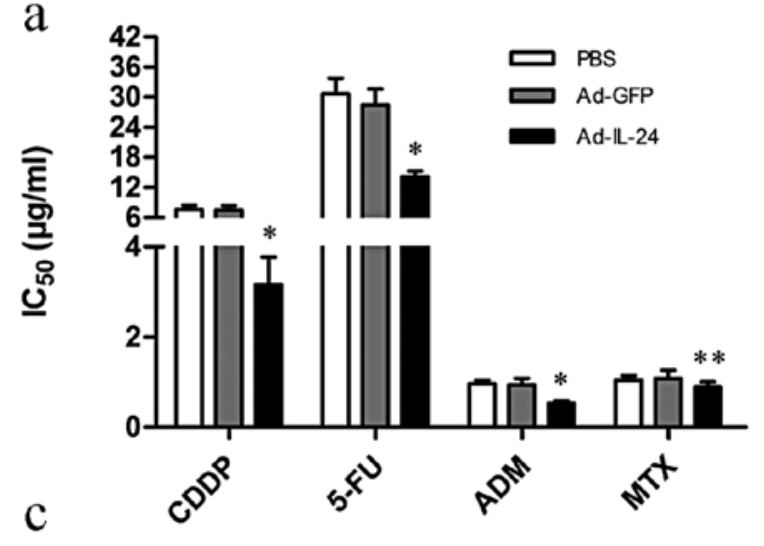

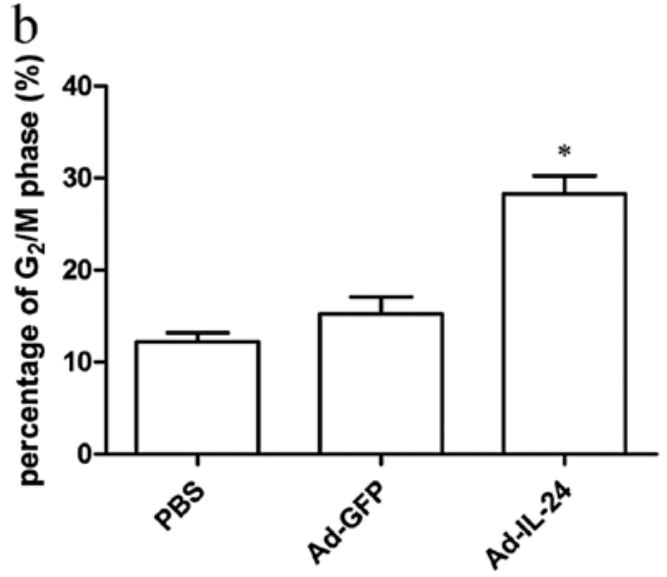
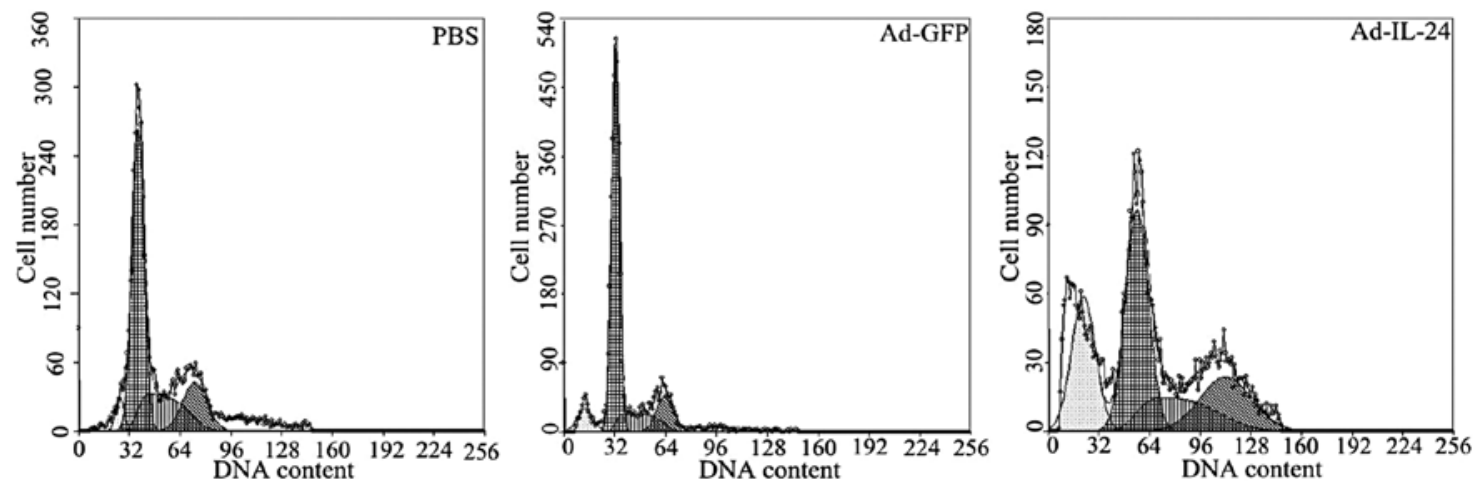

Figure 4. Ad-IL-24 modulates IC $_{50}$ and cell cycle in SGC7901/CDDP cells. (a) Cell viability CCK-8 assay. The IC $_{50}$ of SGC7901/CDDP infected with Ad-GFP or Ad-IL-24 and then treated with CDDP, 5-FU, ADM and MTX were evaluated by CCK- 8 assay. ${ }^{*} \mathrm{P}<0.05$ compared to Ad-GFP and PBS groups, ${ }^{* *} \mathrm{P}>0.05$ also compared to PBS and Ad-GFP groups, respectively, using one-way repeated ANOVA measures and multiple comparisons. $\mathrm{n}=3$ replicates per conditions. (b and c) Cell cycle analysis using propidium iodide staining. Ad-IL-24 significantly induced $\mathrm{G}_{2} / \mathrm{M}$ phase arrest in SGC7901/CDDP cells. * $\mathrm{P}<0.05$ compared to Ad-GFP and PBS groups. one-way repeated ANOVA measures and multiple comparisons. $n=3$ replicates per conditions.
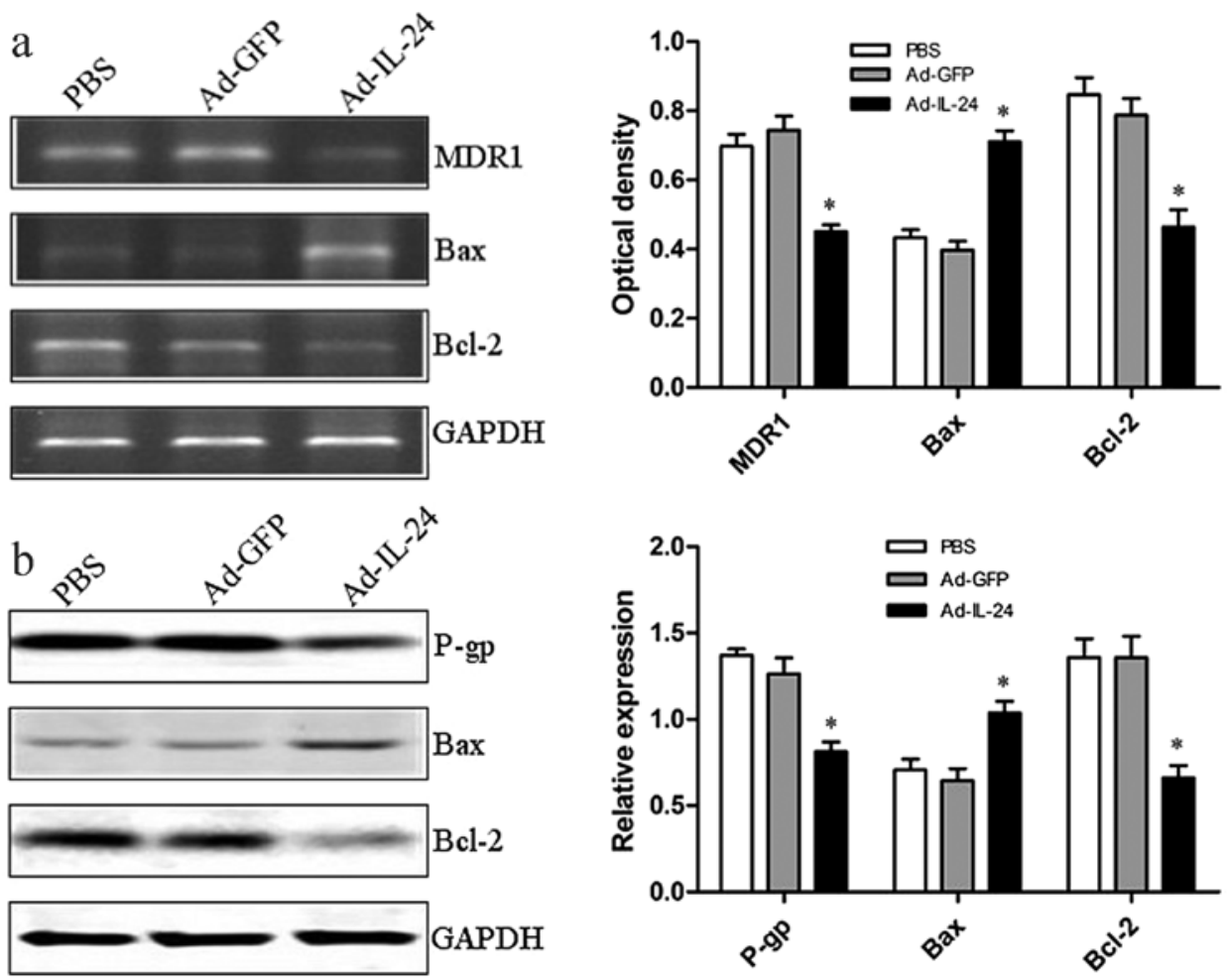

Figure 5. The in vitro chemosensitizing mechanisms of Ad-IL-24 in SGC7901/CDDP cells (a) MDR1, Bax and Bcl-2 transcriptional expression was detected by RT-PCR analysis, ${ }^{*} \mathrm{P}<0.05$ compared to Ad-GFP and PBS groups. One-way repeated ANOVA measures and multiple comparisons. $\mathrm{n}=3$ replicates per conditions. (b) P-gp, Bax and Bcl-2 proteins expression were detected by western blot analysis, ${ }^{*} \mathrm{P}<0.05$ compared to Ad-GFP and PBS groups. One-way repeated ANOVA measures and multiple comparisons. $n=3$ replicates per conditions. 

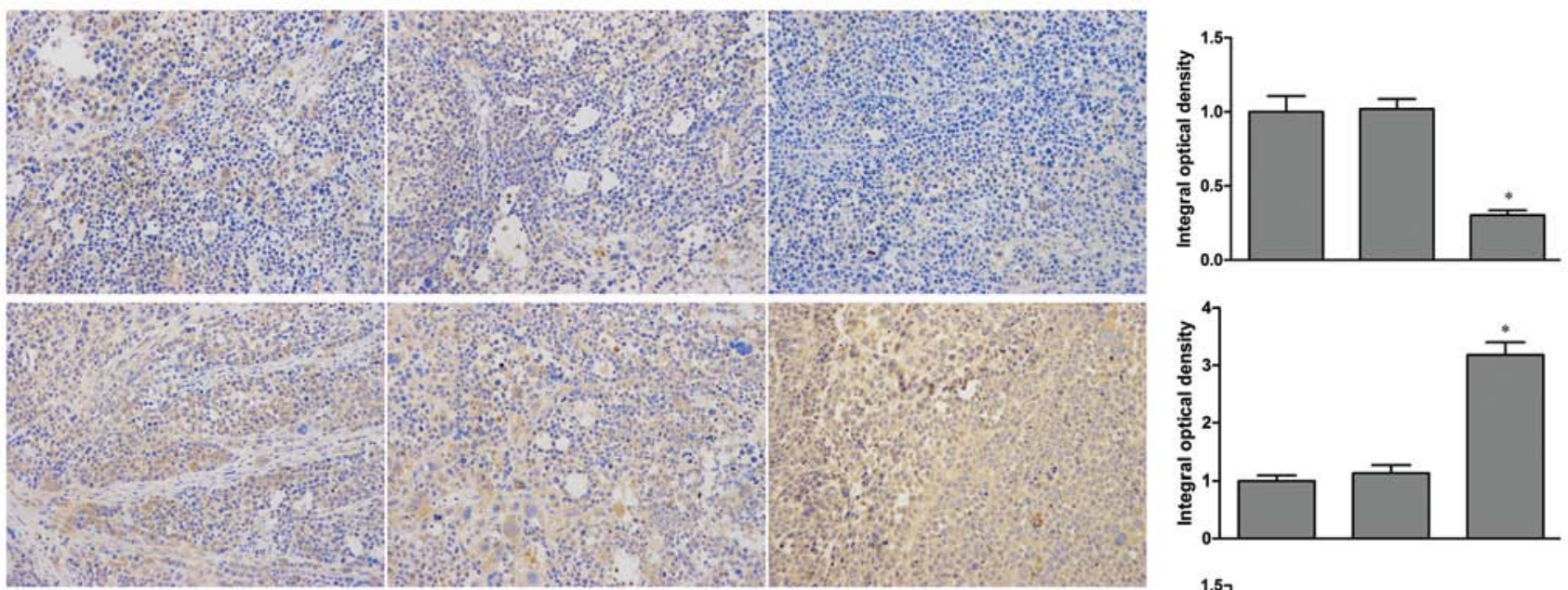

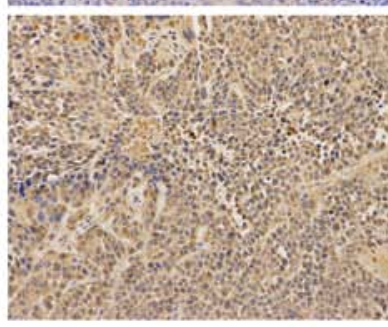

PBS

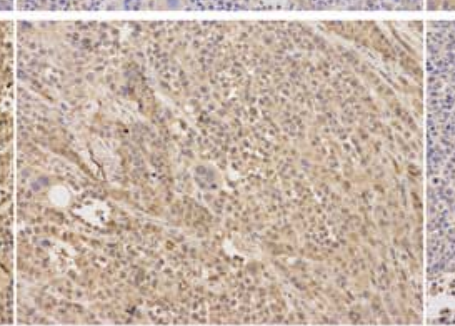

Ad-GFP

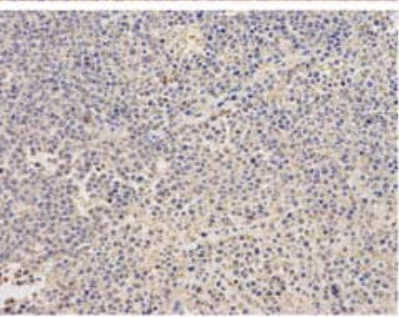

Ad-IL-24

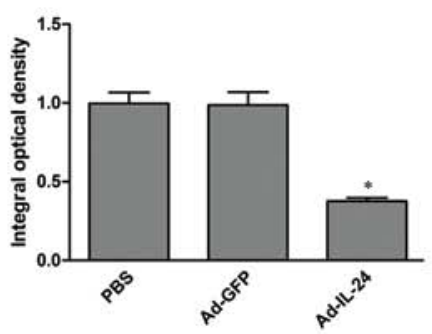

Figure 6. The in vivo chemosensitizing mechanisms of Ad-IL-24 in SGC7901/CDDP cells of nude mouse xenografts. Representative images of immunohistochemical detection of P-gp, Bax, and Bcl-2 in gastric cancer SGC7901/CDDP xenograft tissues. Consequently, the integral optical density (IOD) of immunostaining intensity was quantified by using Image-Pro Plus 6.0 software. ${ }^{*} \mathrm{P}<0.05$ compared to PBS and Ad-GFP groups by using one-way repeated ANOVA measures and multiple comparisons $(n=6$ replicates per condition, $n=5$ observations per representative section). The original magnification was $x 400$. Data shown are representative of three independent experiments.

cytokine gene family, exhibits nearly ubiquitous antitumor properties in vitro and in vivo (11). Unlike other tumor suppressors, the IL-24 unique aspects lie in its selective induction of apoptosis in cancer cells, profound 'bystander' activity by the secreted IL-24 protein, potent antitumor immune response. Some studies demonstrated that the cytotoxic activity of IL-24 gene did not depend on the status of other tumor suppressor genes, such as p53, Rb and ras (33). Furthermore, IL-24 exhibits strong chemosensitizing effects in broad-spectrum MDR phenotype cancer cells $(3,17,23,24)$ and promising results in patients with multiple solid tumors in phase I clinical trials (34). These exciting findings indicate that IL-24 is likely to be a potent nontoxic chemosensitizer for eliminating MDR in tumor cells.

In the current study, we first established a CDDP-induced MDR phenotype gastric cancer subline SGC7901/CDDP by repeated selection and found that MDR promoted resistance of gastric cancer cells to 20 times CDDP treatment or other anticancer drugs, such as 5-FU, ADM or MTX. Then, we assessed the chemosensitizing effects of Ad-IL-24 gene in gastric cancer cells in vitro and in vivo. The results demonstrated that ectopic IL-24 expression decreased the $\mathrm{IC}_{50}$ of CDDP, 5-FU, and ADM (not MTX). Generally, cellular apoptosis often occurs after cell cycle arrest (35), and the anticancer and chemosensitizing mechanism of many treatments is mediated by the induction of cell cycle-specific apoptosis. In our study, we found that Ad-IL-24 significantly increased the percentage of SGC7901/CDDP cells in $\mathrm{G}_{2} / \mathrm{M}$ phase. Ad-IL-24 plus CDDP enhanced the induction of apoptosis in SGC7901/CDDP cells in vitro, and elicited a significant tumor suppression effect in vivo further indicating that Ad-IL-24 could be a potent model of adjuvant chemotherapy for gastric cancer.

Of the 48 human ATP-binding cassette transport proteins (36), $\mathrm{P}-\mathrm{glycoprotein}(\mathrm{P}-\mathrm{gp})$ is the best-known and principal mediator of $\operatorname{MDR}(37,38)$. It extrudes the chemotherapeutic agents out of cancers by using the energy of ATP hydrolysis, resulting in lower intracellular drug concentration and the decline of drug efficacy (39), therefore, is a thorny problem in cancer chemotherapy and inhibition of $\mathrm{P}-\mathrm{gp}$ expression may restore chemosensitivity of cancer cells to anticancer drugs. In our study, overexpression of IL-24 downregulated P-gp expression, and Ad-IL-24 decreased the $\mathrm{IC}_{50}$ of gastric cancer cells SGC7901/CDDP to CDDP, 5-FU, ADM (not MTX). These results demonstrated that decreased expression of P-gp could be a mainstay chemosensitizing pathway. Additionally, Bcl-2 family is a key player in the mitochondrial pathway of apoptosis, which consists of more than 20 members of pro-apoptotic proteins and anti-apoptotic proteins (40). A previous study showed that apoptosis-related proteins (such as Bax and Bcl-2) are also key factors responsible for MDR (30,41-43). The ratio of Bcl-2 family molecules, such as Bcl-2/Bax constitutes the threshold of susceptibility to apoptosis, which promotes pore formation in the mitochondrial outer membrane, loss of mitochondrial integrity, and the release into the cytosol of cytochrome $\mathrm{c}$ followed 
by the cleavage of caspase-9, leading to the activation of intrinsic apoptotic pathway. Our current study demonstrated that Ad-IL-24 significantly induced expression of pro-apoptotic Bax protein, but inhibited expression of apoptosis-suppressing proteins Bcl-2 in vitro and in vivo. Furthermore, Ad-IL-24 plus CDDP enhanced induction of apoptosis in vitro SGC7901/CDDP cells and elicited significant tumor suppression of in vivo of SGC7901/CDDP xenograft tissues. These results demonstrated that intrinsic apoptotic pathway could be another key pathway for Ad-IL24-elicited chemosensitizing in gastric cancer.

Recent evidence has shown that PI3K/Akt, a crucial effectors of the oncogenic signaling pathway, plays a key role in the MDR of gastric cancer cells, and altered expression of P-gp, Bax, and Bcl-2 might be responsible for the PI3K/Akt-induced drug resistance in AGS cells (44-46). Coincidentally, our investigation demonstrated that Ad-IL-24 restores chemosensitivity via modulating the expression of P-gp, Bax, and Bcl-2 in MDR phenotype gastric cancer cells. On the basis of the above evidence, it is believed that $\mathrm{PI} 3 \mathrm{~K} / \mathrm{Akt}$ pathway is very likely to be involved in the Ad-IL24-mediated chemosensitizing effects for gastric cancer. However, our study is just a proof-of-principle and further study will be performed to verify whether PI3K/Akt or some other unknown signaling pathways participate in IL-24enhanced chemosensitivity in gastric cancer cells.

\section{Acknowledgements}

This work was supported by grants from Medical Science and Technology Development Foundation, Suzhou Department of Technology Bureau (no. YJS0916), Medical Science and Technology Development Foundation, Jiangsu, Department of Health (no. H 201013 and H 201209).

\section{References}

1. Jemal A, Bray F, Center MM, Ferlay J, Ward E and Forman D: Global cancer statistics. CA Cancer J Clin 61: 69-90, 2011.

2. Szakacs G, Paterson JK, Ludwing JA, Booth-Genthe C and Gottesman MM: Targeting multidrug resistance in cancer. Nat Rev Drug Discov 5: 219-234, 2006.

3. Emdad L, Lebedeva IV, Su ZZ, Sarkar D, Dent P, Curiel DT and Fisher PB: Melanoma differentiation associated gene-7/ interleukin-24 reverses multidrug resistance in human colorectal cancer cells. Mol Cancer Ther 6: 2985-2994, 2007.

4. Di Nicolantonio F, Knight LA, Glaysher S, Whitehouse PA, Mercer SJ, Sharma S, Mills L, Prin A, Johnson P, Charlton PA, Norris D and Cree IA: Ex vivo reversal of chemoresistance by tariquidar (XR9576). Anticancer Drugs 15: 861-869, 2004.

5. Robert J and Jarry C: Multidrug resistance reversal agents. J Med Chem 46: 4805-4817, 2003

6. Xia L, Zhang D, Du R, Pan Y, Zhao L, Sun S, Hong L, Liu J and Fan D: miR-15b and miR-16 modulate multidrug resistance by targeting BCL-2 in human gastric cancer cells. Int J Cancer 123: 372-379, 2008.

7. Filipits M: Mechanisms of cancer: multidrug resistance: Drug Discov Today Dis Mech 1: 229-234, 2004.

8. Shi Y, Zhai H, Wang X, Han Z, Liu C, Lan M, Du J, Guo C, Zhang Y, Wu K and Fan D: Ribosomal proteins S13 and L23 promote multidrug resistance in gastric cancer cells by suppressing drug-induced apoptosis. Exp Cell Res 296: 337-346, 2004.

9. Zhao Y, You H, Liu F, An H, Hi Y, Yu Q and Fan D: Differentially expressed gene profiles between multidrug resistant gastric adenocarcinoma cells and their parental cells. Cancer Lett 185: 211-218, 2002.
10. Jiang H, Su ZZ, Lin JJ, Goldstein NI, Young CS and Fisher PB: The melanoma differentiation associated gene mda-7 suppresses cancer cell growth. Proc Natl Acad Sci USA 93: 9160-9165, 1996.

11. Dash R, Bhutia SK, Azab B, Su ZZ, Quinn BA, Kegelmen TP Das SK, Kim K, Lee SG, Park MA, Yacoub A, Rahmani M, Emdad L, Dmitriev IP, Wang XY, Sarkar D, Grant S, Dent P, Curiel DT and Fisher PB: Mda-7/IL-24: A unique member of the IL-10 gene family promoting cancer-targeted toxicity. Cytokine Growth Factor Rev 21: 381-391, 2010.

12. Gopalan B, Litvak A, Sharma S, Mhashilkar AM, Chada S and Ramesh R: Activation of the Fas-FasL signaling pathway by mda-7/IL-24 kills human ovarian cancer cells. Cancer Res 65: 3017-3024, 2005.

13. Li YJ, Liu G, Li Y, Vecchiarelli-Federico LM, Liu JC, Zacksenhaus E, Shan SW, Yang BB, Li Q, Dash R, Fisher PB, Archer MC and Ben-David Y: mda-7/IL-24 expression inhibits breast cancer through up-regulation of growth arrest-specific gene-3 (gas 3) and disruption of $\beta 1$ integrin function. Mol Cancer Res 11: 593-603, 2013.

14. Jiang H, Lin JJ, Su ZZ, Goldstein NI and Fisher PB: Subtraction hybridization identifies a novel melanoma differentiation associated gene, mda-7, modulated during human melanoma differentiation, growth and progression. Oncogene 11: 2477-2486, 1995.

15. Xu S, Oshima T, Imada T, Masuda M, Debnath B, Grande F, Garofalo A and Neamati N: Stabilization of MDA-7/IL-24 for colon cancer therapy. Cancer Lett 335: 421-430, 2013.

16. Pataer A, Chada S, Roth JA, Hunt KK and Swisher SG: Development of Ad-mda-7/IL-24-resistant lung cancer cell lines. Cancer Biol Ther 7: 103-108, 2008.

17. Jiang G, Liu YQ, Wei ZP, Pei DS, Mao LJ and Zheng JN: Enhanced anti-tumor activity by the combination of a conditionally replicating adenovirus mediated interleukin-24 and dacarbazine against melanoma cells via induction of apoptosis. Cancer Lett 294: 220-228, 2010.

18. Tong AW, Nemunaitis J, Su D, Zhang Y, Cunningham C, Senzer N, Netto G, Rich D, Mhashilkar A, Parker K, Coffee K, Ramesh R, Ekmekcioglu S, Grimm EA, van Wart Hood J, Merritt J and Chada S: Intratumoral injection of INGN241, a nonreplicating adenovector expressing the melanoma-differentiation associated gene-7 (mda-7/IL24): biologic outcome in advanced cancer patients. Mol Ther 11: 160-172, 2005.

19. Xie Y, Sheng W, Miao J, Xiang J and Yang J: Enhanced antitumor activity by combining an adenovirus harboring ING4 with cisplatin for hepatocarcinoma cells. Cancer Gene Ther 18: 176-188, 2011.

20. Nishikawa T, Ramesh R, Munshi A, Chada S and Meyn RE: Adenovirus-mediated mda-7(IL-24) gene therapy suppresses angiogenesis and sensitizes NSCLC xenograft tumors to radiation. Mol Ther 9: 818-828, 2004.

21. Zhang X, Cheung RM, Komaki R, Fang B and Chang JY: Radiotherapy sensitization by tumor-specific TRAIL gene targeting improves survival of mice bearing human non-small cell lung cancer. Clin Cancer Res 11: 6657-6668, 2005.

22. Moon C, Oh Y and Roth JA: Current status of gene therapy for lung cancer and head and neck cancer. Clin Cancer Res 9: 5055-5067, 2003.

23. Xu J, Mo Y, Wang X, Liu J, Zhang X, Wang J, Hu L, Yang C, Chen L and Wang Y: Conditionally replicative adenovirus-based mda-7/IL-24 expression enhances sensitivity of colon cancer cells to 5-fluorouracil and doxorubicin. J Gastroenterol 48: 203-213, 2013.

24. Fang P, Zhang X, Gao Y, Ding CR, Cui F and Jiao SC: Reversal effect of melanoma differentiation associated gene-7/interleukin-24 on multidrug resistance in human hepatocellular carcinoma cells. Anat Rec 295: 1639-1646, 2012.

25. Chang S, Yang J, Cheng W, Xie Y and Sheng W: Antitumor activity of an adenovirus harboring human IL-24 in colon cancer. Mol Biol Rep 38: 395-401, 2011.

26. Wang X, Ye Z, Zhong J, Xiang J and Yang J: Adenovirusmediated IL-24 expression suppresses hepatocellular carcinoma growth via induction of cell apoptosis and cycling arrest and reduction of angiogenesis. Cancer Biother Radiopharm 22: 56-63, 2007.

27. Gottesman MM, Fojo T and Bates SE: Multidrug resistance in cancer: role of ATP-dependent transporters. Nat Rev Cancer 2: 48-58, 2002. 
28. Choi JH, Lim HY, Joo HJ, Kim HS, Yi JW, Kim HC, Cho YK, Kim MW and Lee KB: Expression of multidrug resistanceassociated protein1, P-glycoprotein, and thymidylate synthase in gastric cancer patients treated with 5-fluorouracil and doxorubicin-based adjuvant chemotherapy after curative resection. Br J Cancer 86: 1578-1585, 2002.

29. Nakamura A, Nakajima G, Okuyama R, Kuramochi H, Kondoh Y, Kanemura T, Takechi T, Yamamoto $M$ and Hayashi K: Enhancement of 5-fluorouracil-induced cytotoxicity by leucovorin in 5-fluorouracil-resistant gastric cancer cells with upregulated expression of thymidylate synthase. Gastric Cancer: Mar. 15, 2013 (Epub ahead of print)

30. Li K, Lu Y, Liang J, Luo G, Ren G, Wang X and Fan D: RhoE enhances multidrug resistance of gastric cancer cells by suppressing Bax. Biochem Biophys Res Commun 379: 212-216, 2009.

31. Zhao L, Pan Y, Gang Y, Wang H, Jin H, Tie J, Xia L, Zhang Y, He L, Yao L, Qiao T, Li T, Liu Z and Fan D: Identification of GAS1 as an epirubicin resistance-related gene in human gastric cancer cells with a partially randomized small interfering RNA library. J Biol Chem 284: 26273-26285, 2009.

32. Kelland L: The resurgence of platinum-based cancer chemotherapy. Nat Rev Cancer 7: 573-584, 2007.

33. Chada S, Mhashilkar AM, Liu Y, Nishikawa T, Bocangel D, Zheng M, Vorburger SA, Pataer A, Swisher SG, Rmamesh R, Kawase K, Meyn RE and Hunt KK: mda-7 gene transfer sensitizes breast carcinoma cells to chemotherapy, biologic therapies and radiotherapy: Correlation with expression of bcl-2 family members. Cancer Gene Ther 13: 490-502, 2006.

34. Eager R, Harle L and Nemunaitis J: Ad-MDA-7; INGN 241: a review of preclinical and clinical experience. Expert Opin Biol Ther 8: 1633-1643, 2008.

35. Fotedar R, Diederich L and Fotedar A: Apoptosis and the cell cycle. Prog Cell Cycle Res 2: 147-163, 1996.

36. Dean M, Rzhetsky A and Allikmets R: The human ATP-binding cassette $(\mathrm{ABC})$ transporter superfamily. Genome Res 11: 1156-1166, 2001.
37. Juliano RL and Ling V: A surface glycoprotein modulating drug permeability in chinese hamster ovary cell mutants. Biochim Biophys Acta 455: 152-162, 1976.

38. Ueda K, Cardarelli C, Gottesman MM and Pastan I: Expression of a full-length cDNA for the human 'MDR1' gene confers resistance to colchicine, doxorubicin, and vinblastine. Proc Natl Acad Sci USA 84: 3004-3008, 1987.

39. Gottesman MM and Ling V: The molecular basis of multidrug resistance in cancer: the early years of P-glycoprotein research. FEBS Lett 580: 998-1009, 2006.

40. Antonsson B and Martinou JC: The Bcl-2 protein family. Exp Cell Res 256: 50-57, 2000.

41. Eberle J, Kurbanov BM, Hossini AM, Trefzer U and Fecker LF: Overcoming apoptosis deficiency of melanoma-hope for new therapeutic approaches. Drug Resist Updat 10: 218-234, 2007.

42. Zhang L, Ming L and Yu J: BH3 mimetics to improve cancer therapy: mechanisms and examples. Drug Resist Updat 10: 207-217, 2007.

43. Zhu W, Shan X, Wang T, Shu Y and Liu P: miR-181b modulates multidrug resistance by targeting BCL 2 in human cancer cell lines. Int J Cancer 127: 2520-2529, 2010.

44. Michl P and Downward J: Mechanisms of disease: PI3K/AKT signaling in gastrointestinal cancers.ZGastroenterol 43: 1133-1139, 2005.

45. Han Z, Hong L, Han Y, Wu K, Han S, Shen H, Li C, Yao L, Qiao T and Fan D: Phospho Akt mediates multidrug resistance of gastric cancer cells through regulation of P-gp, Bcl-2 and Bax. J Exp Clin Cancer Res 26: 261-268, 2007.

46. Yu HG, Ai YW, Yu LL, Zhou XD, Liu J, Li JH, Xu XM, Liu S, Chen J, Liu F, Qi YL, Deng Q, Cao J, Liu SQ, Luo HS and Yu JP: Phosphoinositide3-kinase/Akt pathway plays an important role in chemoresistance of gastric cancer cells against etoposide and doxorubicin induced cell death. Int J Cancer 122: 433-443, 2008. 